\title{
Introduction to CD-ROM Production in Health Education
}

\author{
Mark Tomita \\ California State University, Chico
}

\begin{abstract}
Compact disc (CD-ROM) computer technology have been around for at least a decade, but health educators have been slow to use this technology for health education purposes. This paper describes the process of CD-ROM production in health education.

(C) 2003 Californian Journal of Health Promotion. All rights reserved.

Keywords: CD-ROM, technology, health education, information technology
\end{abstract}

\section{Introduction}

Compact disc (CD-ROM) computer technology has been around for at least a decade, but health educators have been slow to use this technology for health education purposes. Although entrylevel health educators are not expected to have defined competencies in producing health education materials on CD-ROMs, the technology is useful for health educators to know. CD-ROM technology is taught at the California State University, Chico, to health education undergraduate majors enrolled in HCSV 060 Computer Applications in Health Education. With CD-ROMs, health education programs are digital, portable, conveniently located on one's desktop, and is only a mouse click away. Accessing the Internet is not necessary, nor is going to the public library to access the same health information. Accessibility to the CD-ROM health information has made this technology valuable to health education.

The purpose of this paper is to discuss the process of producing CD-ROMs for health education purposes. The Global Health Disparities CD-ROM Project, a collaborative venture between the California State University, Chico, and the Society for Public Health Education (SOPHE), will be used as an example to illustrate the points being made. Helpful advice for developing the content and format of the health education CD-ROM is presented below. The materials needed and the process of how CD-ROMs are reproduced are discussed.

\section{Developing the CD-ROM Content}

As with any health education program, clearly defined goals, objectives, and intended population are essential. Traditional health education program planning models may be used to design a health education program on CD-ROM. The addition of Davis' $(1989,1993)$ technology acceptance model (TAM), an enduser technology theory, may be integrated into program planning.

Davis' TAM is ideal for use with CD-ROM health education programs. According to the model, people are more likely to use a technology if it is easy to use and useful. The perceived ease of use relates to the design of the $\mathrm{CD}-\mathrm{ROM}$ whereas perceived usefulness relates to the content of the CD-ROM.

The user skill level of the intended population needs to be assessed to determine what design elements can be introduced into the CD-ROM. For example, having advanced features such as keyword searches or database manipulation on a CD-ROM may be not be appropriate for novice computer users. Such advanced features may be better suited for advanced users who are skilled at foraging for information. For example, a CDROM designed with bright colors, talking heads, animations, and large icon links is more consistent with a design for children and teens. 
Such a design would not be appropriate for a professional CD-ROM. A conservative design with a white or pastel-colored background with black text may be more appropriate. The CDROM designer needs to know the intended population of the CD-ROM.

It is implied that the intended population for the CD-ROM will have some level of computer skills and will have access to a computer with a CD-ROM drive. There is no point in designing a health education CD-ROM for people who have no computer skills and no easy access to a computer with a CD-ROM drive. This assumption leads to interesting questions regarding who actually benefits from health education CD-ROMs. Many people who are poor or are uneducated may not have access to computers or may not have sufficient skills to use health education CD-ROMs.

\section{Choosing the Computer Platform}

Choosing the computer platform (PC or Macintosh) may be necessary to limit the amount of work required to complete the project. Most health educators use PCs and not Macintoshes, thus, if the CD-ROM is intended for health educators, the CD-ROM should be produced in PC rather than Mac. School teachers, however, may want to create CDROMs for a Macintosh platform because many school districts use that platform. It is possible to produce hybrid CD-ROMs (to be read by PC and $\mathrm{Mac}$ ), although this is not always necessary because the newer models of Macintoshes should be able to read PC CD-ROMs, with only minimal problems.

\section{Choosing the Primary User Interface}

As a rule, creating CD-ROMs that can "stand alone" or function without having unusual software and hardware to run the CD-ROM is preferable. Two primary user interfaces, HTML and MS PowerPoint ${ }^{\circledR}$, are ideal for use in health education because most users have a web browser on their desktop or have access to MS PowerPoint ${ }^{\circledR}$. Other software applications such as Greenstone Digital Library Software (University of Waikato, 2002), require the installation of the Greenstone suite of software on a user's computer. It is an excellent resource for developing very large libraries of health information, but if the intended users will avoid using the CD-ROM because it requires them to install an unusual software application, they are less likely to use the CD-ROM.

The HTML format is identical to the design of web pages, but rather than creating multiple levels of directories, it may be better to place the HTML files in one directory to avoid problems with links having to go up a directory or two. Other files, such images and PDF documents could be placed in lower directories where users simply use the Back button to return to the main menu. There needs to be a home page as any web site. The home page will orient the user to what is on the CD-ROM, and will provide for better navigation.

The HTML format combined with primarily PDF documents were used for the Global Health Disparities CD-ROM Project. Having some knowledge of the intended audience (members of the Society for Public Health Education), the Project Team decided to create the CD-ROM in HTML with most of the documents in PDF. Many health educators, including those in SOPHE, are skilled users of web browsers such as MS Internet Explorer ${ }^{\circledR}$ and Netscape ${ }^{\circledR}$. Thus, perceived ease of use would be viewed positively. Since there were over 700 resources on the CD-ROM, it was anticipated that the CDROM would be viewed to be very useful. Positive perceptions of ease of use and useful promoted use of the CD-ROM by SOPHE health educators.

One must take into consideration the goal of the CD-ROM and the use of the HTML format. The goal of the Global Health Disparities CD-ROM was to build capacity of the public health education workforce by providing health educators with primary resources on global health disparities. Providing health educators with primary resources would better enable them to meet the challenges of programming designed to eliminate health disparities. The goal of a consumer health education CD-ROM, however, is to educate lay persons and to present information about health. The Global Health Disparities CD-ROM was simply a library of 
republished primary resources without much "educating" other than making the health educators aware of where to obtain resources on the web. The documents themselves provided information about health disparities. An actual health education CD-ROM for consumers, however, will need to be more than simply having links to primary resources. The CDROM format must accommodate interactivity, especially when the intended audience is children. Fortunately, the HTML format is suited for interactivity, and may be used for consumer health education programs.

The HTML format is also ideal for use with college faculty. Faculty may use CD-ROMs to distribute materials to their students such as syllabi, reading lists, tutorial materials, large datasets, and other resources. CD-ROMs for distance learning students to use rather than having to access online materials that are difficult to download is one option that may be worth exploring. CD-ROMs for college students still need to have a main page, table of contents, or main menu where the user may view all of the contents of the CD-ROM and may be informed about how to navigate and find information.

The MS PowerPoint ${ }^{\circledR}$ format is a user interface that may be used on a CD-ROM. It is ideal for health educators planning to create multimedia presentations in a step-by-step format. Complex links may be formed between slides to navigate the CD-ROM and to access more detailed information about a particular health topic. The PowerPoint ${ }^{\circledR}$ format is also ideal for selflearning health education modules and slideshows for health education professional development. Many health educators already use PowerPoint for presentations at conferences. These presentations, if designed with more explanation about the content, could be used on CD-ROMs as self-learning modules.

One design issue when using PowerPoint on a CD-ROM is whether to use a modular or linear slideshow format. The PowerPoint slideshow feature allows the CD-ROM designer to create a series of slides to be played in sequence. Rather than being locked into a linear, sequential slideshow, it may be better to create a modular format where the user enters a home page much like the format used for HTML. The home page will serve as a main menu to a series of slide sets. Template navigation bars may be inserted on each slide for ease of use.

\section{Organizing Materials on the CD-ROM}

The organization of materials should be consistent with the format selected above, and the scope and sequence should follow standard educational practices.

When the Global Health Disparities CD-ROM Project first began, some team members wanted the documents organized into meaningful health disparities content and process areas. Many government agencies and organizations granting permission to republish their materials on the CD-ROM, however, requested that all of their materials must remain on the same page, and a disclaimer, address, or some other detail had to be noted at the bottom of their page. Thus, the materials had to be listed on separate HTML pages, and could not have been organized into content and process areas. At the end of the project, just before publishing, the documents were organized into content and process areas only after satisfying the republishing agreements with the government agencies and organizations.

\section{CD-ROM Support Utilities}

The first utility that may be needed is a keyword search engine. Companies license HTML keyword search engines, for example, Search Maker Pro ${ }(\underline{C D R}, 2003)$. Rather than licensing a keyword search engine, users always have the option of using the Start Menu > Search method of finding documents on the CDROM or alternatively, conduct a within document search in files such as MS Word $\AA$ or MS PowerPoint $\AA$. To conduct a within document search, the user will have to access Edit Menu $>$ Find.

If many of the documents on the CD-ROM are in Adobe Portable Document Format (PDF), a PDF search engine (archive) may be created. Be aware that on a 700 MB CD-ROM with hundreds of documents, the PDF archive may take up to $50 \mathrm{MB}$. Thus, no more than $650 \mathrm{MB}$ of materials may be stored on any CD-ROM. 
Also, the users may need the current version of Acrobat Reader ${ }^{\circledR}$, so you will need to include a copy of the current version on the CD-ROM for users to install on their computers. Upgrading software applications over the web may take a long time, thus, having the Acrobat Reader ${ }^{\circledR}$ installed from the CD-ROM is convenient. It may be better to include at most $630 \mathrm{MB}$ of materials on the CD-ROM, leaving enough room to add a PDF search engine and any software applications your users might need.

Creating an Adobe Acrobat PDF archive for use in keyword searching of PDF documents was necessary for the Global Health Disparities CDROM. A Browse design alone where the user accessed pre-sorted information was not feasible for the CD-ROM because there were far too many documents, and many health educators would expect a search tool (again, perceived usefulness) to forage for information. The PDF search function was the only acceptable form of search. On the web, web site developers may install CGI scripts to execute searches, but these scripts are executed from a network computer. Such CGI scripts will not work if the documents are on a CD-ROM. Thus, CD-ROMs need search engines that are stand alone systems.

One problem with PDF search engines is that the full version of Acrobat is needed to access the PDF search engine. Many health educators do not have the full version of Acrobat.

The second utility that may be needed on the $\mathrm{CD}-\mathrm{ROM}$ is the autorun script (Autorun.inf) placed at the root of the CD-ROM. An autorun script causes the CD-ROM to open automatically to the main page of the CD-ROM. Windows ${ }^{\circledR}$ has a built-in feature for opening .exe files, but does not have the ability to open other file extensions such as .htm/.html. This problem is readily solved by obtaining an HTML autorun script. In the autorun script example below, the autorun script is telling the ShelExec file that when the CD-ROM is inserted into the CD-ROM drive, automatically open the file named "index.htm".

\section{[autorun] OPEN=ShelExec index.htm ICON=test.ico}

The next line of the script tells the PC to display the icon file named "test.ico," a 16 X 16 pixel icon file. ICO files can be created using either freeware (Smyth, 2002) or proprietary software applications such as Favicon ${ }^{\circledR}$. The test.ico icon will be displayed in place of the standard My Computer CD-ROM Drive icon.

Search engines and autorun scripts are not necessary, however, it may make the CD-ROM to be perceived as easier to use, useful, and professional.

Planning: Evaluating Resource Availability Now that the CD-ROM content and format have been selected, and a master CD-ROM has been produced, the health educator needs to decide how the CD-ROMs will be reproduced, labeled, and packaged. An assessment to determine what resources are available for the job must be conducted:

1. Funds- How much money is available for the project? Producing CD-ROMs may be as low as \$.40 USD per CD-ROM or as high as $\$ 4$. USD per CD-ROM. The costs for shipping, handling, and taxes will need to be added, especially if the CD-ROM is being sent to a commercial printer.

2. Materials- What equipment and software applications are available to reproduce CD-ROMs in-house? As will be discussed later, the cost of purchasing equipment to reproduce and label CDROMs is expensive.

3. Personnel- If the CD-ROM is produced in-house, what trained personnel are available to reproduce, label, and package the CD-ROMs? Also, a graphic artist will be needed to design a label that is suitable for printing. Graphics used in commercial printing is of higher quality than that of graphics used in common desktop applications, and must be in an acceptable file form. 
4. Elaborate Packaging- Is it acceptable for the CD-ROM to look like it was produced on a shoestring budget or must the $\mathrm{CD}$ ROM have all the bells and whistles? Labeling and packaging may add considerably to the costs of producing the CD-ROM.

5. Time- How much time is available to complete the project? Single CD-ROM burners could be used to duplicate small numbers of CD-ROMs, but this process is time consuming, and may not be suitable for the production schedule if large numbers of CD-ROMs are needed. Using student workers and interns to assist with the project is always an option.

In the case of the Global Health Disparities CDROM, the decision to send the CD-ROM to a printer for replication, labeling, and packaging was based on several factors: 1) $1000 \mathrm{CD}$ ROMs were needed for the project ( 800 for distribution to health educators, and 200 for complimentary copies to governments and organizations that participated in the project), 2) the short CD-ROM production time, 3) the lack of equipment available to produce the CD-ROM in-house at a reasonable cost, and 4) the availability of a graphic design student to design the label that would meet printing standards using Adobe PhotoShop ${ }^{\circledR}$.

\section{CD-ROM Technology Basics}

CD-ROM technologies are not as complicated as they may seem. The CD-ROM developer will need to choose the type of compact disc, reproduction method, label, labeling method, and packaging. A major decision will have to be made in the planning stages of the health education project, and these decisions revolve around time and money. In-house duplication is sometimes cheaper than sending the job to a printer. However, having a professional printer take care of the jobs saves a lot of time and aggravation. If the job is small (less than 100 CD-ROMs) and there is sufficient amount of time and money, an in-house production may be the best alternative. However, if the number of CD-ROMs needed exceed 100, it may be better in the long run to have someone else replicate, label, package, and deliver the CD-ROM.

\section{CD-ROM Media (the dises)}

The choice of CD-ROM media is important, mainly if you will be producing the CD-ROM in-house. When producing CD-ROMs, you will need to determine what type of CD-ROM you want to use. There is a variety of discs to choose from. Most have similar specifications. You will need to make decisions about the: 1) size in $\mathrm{MB}$ or recording minutes, 2) color, 3) branded or blanks, 4) volume packing, 5) Read Only or Read/Write (CD-R and CD-RW), 6) speed of recording $1 \mathrm{X}-40 \mathrm{X}$, and 7) coating on the top surface of the CD-ROM.

CD-ROMs are usually 650 or $700 \mathrm{MBs}$ in capacity. The $700 \mathrm{MB}$ CD-ROMs also record 80 minutes of audio. The standard colors for CD-ROMs are silver, gold, and diamond. Other colors are available.

Many CD-ROMs are branded with the company name stamped on the top surface. Blank CDROMs are usually silver, gold, or diamond, with a lacquer finish on the top side of the CD-ROM and silver or some other color on the bottom. You will need the unbranded or "blank" CDROMs if you are planning to print a label directly to the surface. If you are planning to "stomp" or adhere a paper label to the CDROM, using the branded CD-ROM will probably be OK because the brand name will be covered by the paper label. Some of the brandnamed CD-ROMs you may see are Mitsui ${ }^{\circledR}$, Taiyo-Yuden ${ }^{\circledR}$, TDK ${ }^{\circledR}$, Maxwell ${ }^{\circledR}$, Verbatim ${ }^{\circledR}$, and Prodisc $\AA$.

Some CD-ROM surfaces may be OK for printing inkjet or thermal labels directly to the surface of the CD-ROM. When purchasing blank CD-ROMs, the specifications should be listed with the product, for example, it may say, "CD-R $700 \mathrm{MB} / 80$ min 32X, blank white inkjet, 100 pk."

CD-ROMs come in packs of 10, 30, 50, 100, 300 , and larger. Some are boxed, while others come on a spindle. The CD-ROMs will likely be packed with shrink wrapping around the discs 
to prevent movement during transport. $\mathrm{Be}$ aware that a small percentage of CD-ROMs may not be readable by the duplicator. Thus, if a health educator is producing $100 \mathrm{CD}-\mathrm{ROMs}$, it will be wise to purchase at least 120 . Test copies may need to be made to test the search engine and autorun script.

CD-Rs (Read Only) are CD-ROMs that once information is copied to the disc and finalized, no other information may be copied to the disc. CD-RWs (Read/Write) are CD-ROMs that function like a floppy disk. However, for health education purposes, CD-Rs should be used. This format will prevent altering of the copyrighted materials on the CD-ROM.

The speed at which a CD-ROM is capable of recording data to it is $1 \mathrm{X}-40 \mathrm{X}$. While this may be theoretically true, it is more than likely that a CD-ROM will be recorded at 40X. A more realistic speed is $24 \mathrm{X}$. A $700 \mathrm{MB}$ CD-ROM may take up to $10-15$ minutes to be fully recorded and finalized (including removing and replacing CD-ROMs from the drive). This means that a maximum number of CD-ROMs that may be recorded per $\mathrm{PC}$ is 4 per hour.

The coating on the CD-ROM will depend upon what method of labeling you will choose. Some CD-ROMs are designed for printing directly to its top surface. This issue will be explored in more detail below.

\section{CD-ROM Reproduction Methods}

There are two methods to reproduce CD-ROMs. The first method is duplication, and is a similar process to that used by single CD-ROM Writers on desktop PCs. The duplicator may have multiple drives stacked on each other, may be manual or autoloading (the machine automatically inserts and removes the CD-ROM from the drive), connected to a $\mathrm{PC}$ or stand alone, and may have a labeling attachment so that the CD-ROM is duplicated and then labeled (see auto-duplicators from Rimage, Figures 1 and 2).

Mass produced CD-ROMs are usually replicated through an injection molding process, and not duplicated using CD-ROM Writers. Glass molds are made from the master CD-ROM and plastic is injected into the mold, similar to the process of how music records were made. Usually when CD-ROMs are mass produced by CD-ROM printers, the CD-ROMs are molded rather than "burned."

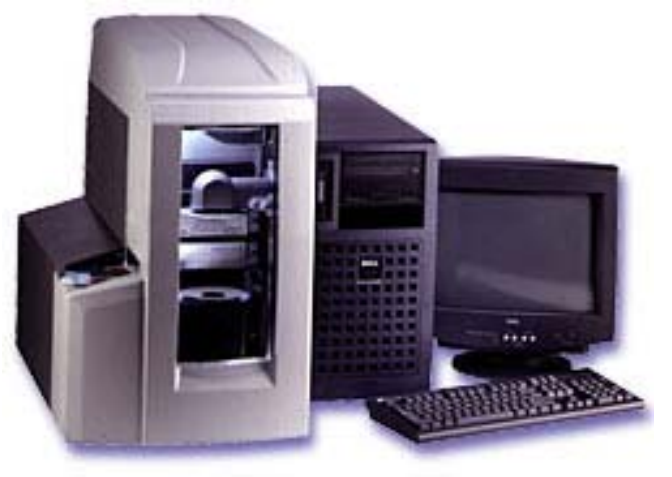

Figure 1

Protégé II. Autoduplicators from Rimage (Rimage, 2002).

Photos reprinted with permission from Rimage.

\section{CD-ROM Labeling}

There are several options to label the CD-ROM. Paper labels may be printed and "stomped" on each CD-ROM, labels may be printed directly to the surface of the CD-ROM using inkjet or thermal CD-ROM label printers, or labels may be silk-screened by a professional printer.

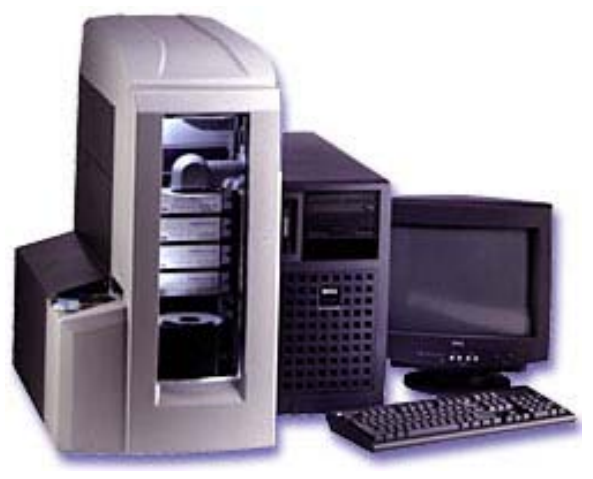

Figure 2

Autostar II Autoduplicators from Rimage

(Rimage, 2002)

Photos reprinted with permission from Rimage. 
Paper label kits may be purchased and printed using either regular paper inkjet printers or CDROM inkjet printers (see below). Both matte and glossy finished labels are available. Once the paper labels have been printed, the label is adhered to the top surface of the CD-ROM. The adhering process is often referred to as "stomping," and has become a popular method among consumers to label their music CDROMs. Most professionally done CD-ROMs, however, do not have paper labels. Most CDROM labels are directly applied to the CD-ROM surface using inkjet printers, thermal printers, or silk screening.

\section{CD-ROM Label Printers}

Two types of CD-ROM label printers are available: inkjet and thermal. Both printers print directly to the surface of the CD-ROM without paper labels. The most inexpensive model of manual printers (you insert a blank $\mathrm{CD}-\mathrm{ROM}$ onto the printing platform and remove the printed CD-ROM yourself) inkjet printers is the EZ/CD 5700 Color Inkjet CD Label Printer which costs about \$359. USD online, and will print on CD-ROMs and paper labels. These types of inkjet printers have similar ink cartridges and cables to that of inkjet printers for printing on regular paper. Software and templates are usually bundled together with these printers for creating labels. Protective sprays are available for inkjet labels to prevent discoloration and scratching.

The Primera Signature IV CD-ROM Inkjet Printer is a manual high resolution printer which costs over $\$ 1,000$. USD (Figure 3). Autoloading inkjet printers run as low as $\$ 1,000 .-2,000$. USD to as high as over $\$ 8,000$. USD.

The thermal label printer is an alternative to the inkjet printer. Thermal printers transfer ink from a ribbon to the top surface of the CD-ROM via heat. Both inkjet and thermal printers produce excellent quality labels.

Thermal label printers tend be higher in costs than inkjet, and the average cost ranges from $\$ 2,000$. USD to over $\$ 8,000$. USD. Figure 4 shows two thermal printers, the Perfect Image Prism Plus and Rimage Everest Printer (Rimage,
2002). Primera also has a line of thermal CDROM label printers.

Figure 5 is the Primera Bravo, an autoduplicator with inkjet CD-ROM printer. Although Primera and Rimage products tend to be higher priced than printers you may be able to obtain, the quality of printing and reputation of these products in the industry are unsurpassed.

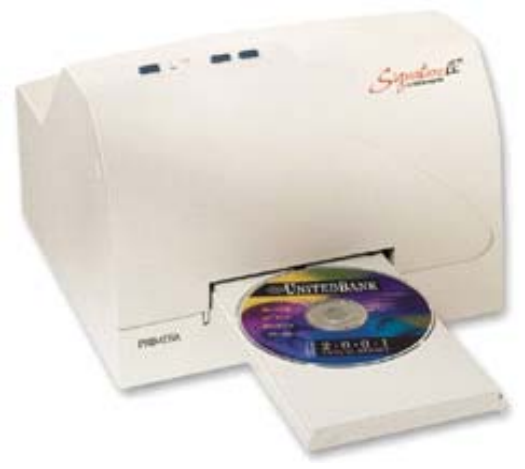

Figure 3

Primera Signature IV CD-ROM Color Printer. Photo reprinted with permission from Primera.

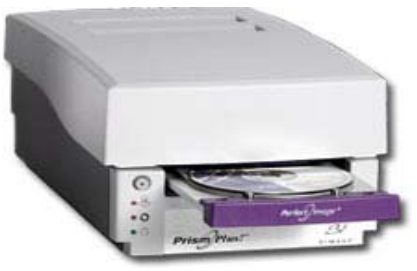

Perfect Image Prism Plus

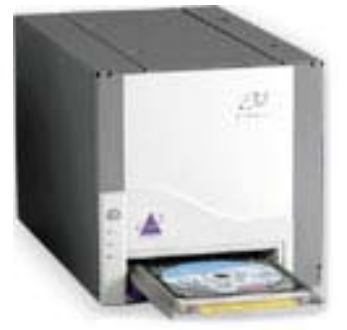

Figure 4

Rimage Everest Printer Standalone

Thermal Printers from Rimage.

Photos reprinted with permission from Rimage. 


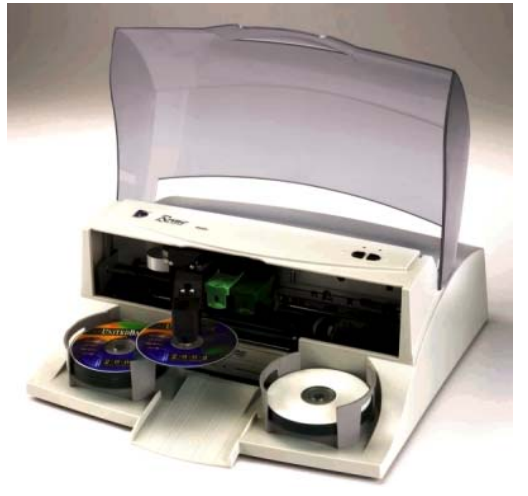

Figure 5

The Primera Bravo is an autoduplicator with inkjet label printer. Photo has been reprinted with permission from Primera.

The decision to produce CD-ROMs in-house is largely dependent upon the amount of available start-up funds to do this. If health educators are part of a large organization, it may be worthwhile to invest in the equipment to be able to label your own CD-ROMs, especially when the orders tend to be small, around 50-100 CDROMs. With desktop and user friendly equipment, it is convenient to publish small orders in-house rather than sending the job to a printer for replication, labeling, and packaging. The turn-around time will probably be shorter, and the costs far less than what you would pay a professional printer.

\section{Packaging}

The finished product with a nice label requires packaging to protect the CD-ROM. Shrinking wrapping around the CD-ROM packaging is optional. Most printers offer both packaging and shrink wrapping services. There are several choices of packaging: Jewel case (standard plastic CD-ROM case with lid), hard plastic, cardboard jackets (up to 8 panels), cardboard mailers, Tyvek ${ }^{\circledR}$ and vinyl sleeves, and cardboard/paper sleeves. The jewel case and cardboard jackets are standard packaging methods. The most inexpensive yet acceptable method of packaging is the paper sleeve with a window and flap. The CD-ROM label will show through the window, and is sufficient to make the product look professional. Paper sleeves costs as little as \$.05 USD each. A wide selection of packaging may be seen online at eDoc.

\section{Other Publishing Matters}

There are usually two issues health educators are interested in when it comes to publishing CDROMs. First, copyright for the health education CD-ROM publication may be filed through the US Copyright Office (US Copyright Office, 2002). All of the information about copyrighting, fees, and forms are all available through the web site (see Table 1). Second, the Library of Congress, National Serials Data Program handles assignments of International Standard Serial Numbers (ISSN). For those health educators who are planning to publish a serial in the form of a CD-ROM, an ISSN number should be obtained. If the publication is also in print or some other form, separate ISSN applications need to be filed for each form of the serial publication (paper, CD-ROM, and Internet). The Library of Congress web site has all of the information and online forms necessary to complete the ISSN filing.

\section{Health Education Implications}

Health educators need to take advantage of CDROM technology to make accessible health information that is readily retrieved on the desktop. Program planning and evaluation models with end user technology models provide a conceptual framework to guide the development process. The goals, objectives, intended population, funding, and other issues will ultimately shape the end product. CDROMs may be produced in-house or may be sent to professional printers.

The Global Health Disparities CD-ROM Project undertaken by Chico State and SOPHE was an attempt to build capacity of the public health education workforce to meet the challenges of eliminating health disparities through public health education. It is becoming more evident that there needs to be greater accessibility by health educators to health information on CDROMs. Health educators may spend weeks looking on the web and searching academic databases for information. Such information could easily be provided on CD-ROM by 
government, academic institutions, and health education professional associations, forming coalitions and partnerships, to complete CDROM projects. Having information on the desktop will save health educators in the trenches a lot of time and money that are better spent on the populations they serve.
The California State University, Chico, is committed to continuing a series of CD-ROM projects with professional association groups such as the SOPHE International and CrossCultural Health Special Interest Group (ICCHSIG) and the SOPHE United Nations Representatives to build capacity of the public health education workforce.

Table 1*

Exploring online resources for CD-ROM production.

\begin{tabular}{|c|l|}
\hline \multicolumn{1}{|c|}{ Company } & \multicolumn{1}{c|}{ URL } \\
\hline CD-ROM Information & $\underline{\text { http://www.cd-info.com }}$ \\
\hline CD Information Center & $\underline{\text { http://buyaleratec.com }}$ \\
\hline Online Stores & $\underline{\text { http://www.atdiscounts.com }}$ \\
\hline Alera Technologies & $\underline{\text { http://www.cds.com/ }}$ \\
\hline AT Discounts & $\underline{\text { http://www.runtechmedia.com }}$ \\
\hline CD Store & $\underline{\text { http://www.silvercenturyinc.com/ }}$ \\
\hline RunTechMedia.com & \\
\hline CD-ROM Replication & \\
\hline Silver Century Inc. (Newark, CA) & $\underline{\text { http://www.primeratechnology.com }}$ \\
\hline Manufacturers & $\underline{\text { http://www.rimage.com }}$ \\
\hline Primera Technology, Inc. & $\underline{\text { http://www.loc.gov/copyright/ }}$ \\
\hline Rimage & $\underline{\text { http://www.loc.gov/issn/ }}$ \\
\hline Other & \\
\hline US Copyright Office & \\
\hline National Serials Data Program & \\
\hline
\end{tabular}

* These companies are not endorsed by the author or CJHP. The online sources are provided for readers to explore what CD-ROM-related resources are available to them for producing their own health education CD-ROMs.

\section{References}

CDR. (2003). Search maker pro. Retrieved February 11, 2003, from http://www.searchmakerpro.com/. Library of Congress. (2002). National serials data program, international standard serial number (ISSN). Retrieved February 11, 2003, from http://www.loc.gov/issn/

Primera Technology, Inc.. (2002). Primera Technology, Inc. home page. Retrieved February 11, 2003, from http://www.primeratechnology.com

Rimage Corporation. (2002). Rimage Corporation home page. Retrieved February 11, 2003, from http://www.rimage.com/

Smyth, R. (2002). Icon maker. Retrieved February 11, 2003, from http://www.simtel.net/pub/pd/5914.html

University of Waikato. (2002). Greenstone Digital Library Software. Retrieved February 11, 2003, from http://www.greenstone.org/english/home.html

US Copyright Office. (2002). US Copyright Office home page. Retrieved February 11, 2003, from http://www.loc.gov/copyright/ 


\section{Acknowledgements}

The author would like to thank Primera Technology and Rimage Corporation for granting permission to republish the photos of their products in this article.

This paper was supported by a 2002 Strategic Performance Fund Grant to the author from the California State University, Chico, College of Behavioral and Social Sciences, and the Department of Health and Community Services.

This article is a condensed version of a CD-ROM guidebook by the author.

Author Information

Mark Tomita, PhD, RN, CHES

Department of Health and Community Services

California State University, Chico

Chico, CA 95929-0505

E-Mail: mtomita@csuchico.edu

Mark Tomita teaches HCSV 60 Computer Applications in Health Education, and has introduced CD-ROM technologies into the undergraduate health education curriculum. 